\title{
Sliding Wear Test and Also SEM Study on Epoxy Reinforced Glass Fibre Composite Along with the Fillers of Black Granite Powder, White Granite Powder as Well as Stone Powder
}

\author{
${ }^{1}$ D. K. Jawad, ${ }^{2}$ Dr. A. Ramesh \\ ${ }^{1,2}$ Department of Mechanical Engineering, \\ JJTU, Jhunjhunu, Rajasthan-333001.
}

\begin{abstract}
SEM assessment in addition to wear test on Epoxy composite reinforced Glass fibre alongside the fillers of Black Granite Powder, White Granite Powder as well as likewise Stone Powder with considering 10 test instances of 3 alternatives of $5 \%, 10 \%$ as well as additionally $15 \%$ weight per-cents of fillers. Scanning electron microscopy (SEM) used to analyze the composite microstructures. A risky research study on Sliding Wear test conducted to determine the wear, coefficient of friction as well as additionally friction force through taking advantage of a wear testing machine as well as additionally the wear methods of reinforced Epoxy together with Glass fibre in addition to filler matrix were really examined as well as additionally the specific wear costs of the Glass epoxy composite together with as well as additionally without fillers were really reviewed.
\end{abstract}

Key words: Epoxy, Glass fire, Black Granite powder (BGP), White Granite powder (WGP), Stone powder (SP), Wear, Specific wear rate, Coefficient of friction, Sliding Distance.

\section{INTRODUCTION:}

Polymer is actually an artificial all natural material features little particles recognized as monomers, Epoxy is actually a functional course of particle including one air atom adhered along with pair of carbon atoms and also these carbon atoms actually have actually bound through various other methods, glass fibre being composed very little fibre coatings of glass and also granite as well as stone powder are actually the commercial wastefulness gotten after grinding the granite and also rocks.

Epoxy material reinforced along with artificial fibres including glass fibre is actually anenormous accomplishment in the business of materials. The combos of polymer based upon composite materials have actually begun brand new methods for the polymer assembly and also have actually permitted the manufacture of brand new items along with ideal properties [2].

Fillers of Granite and also Stone grains happened under the course of ceramic, these are actually included the kind of powder that indicates featuring remarkably little surfaces and also each surface kind as a clear that connections properly along with Glass fibre Epoxy as well as improves mechanical properties including tensile, flexural, impact, hardness toughness as well as likewise improves the perspective security, protection to wear, operate at heats, enduring protection.
It is actually typically acknowledged to make use of the SEM devices is actually direct to function; it is actually a notable component in the research of mini constructs at the failing aspect of the all evaluated examples [18].

There are actually comprehensive specialized requests through which friction and also wear are crucial factors to consider. Polymer composites having various fillers as well as supports [17].

Among the necessary features of materials are actually wear and also friction. Wear is actually determined as the damage to a strong area, typically pertaining ongoing reduction of material, because of moving activity in between that area as well as speaking to drug or even compounds [12]. To boost the friction as well as wear properties of polymer materials is actually to enhance their hardness, tensile, impact as well as flexural durabilities as well as to minimize their attachment to the getting in touch with component material for this normally making use of the fibre encouragements along with the glass fibre as well as ceramic fillers in the powder kind [9].

\subsection{Work Sample Preparation:}

A Teflon glass mould of measurements $300 \times 200 \times 3$ $\mathrm{mm}^{3}$ has actually readied, reduced the called for dimension of glass fibre at that point use the silicon mould launch spray on the internal surface area of Teflon glass mould and after that use 1st coating of Epoxy as received Fig.1, insert the 1st level of glass fibre on it as well as use the $2^{\text {nd }}$ coating of Epoxy on glass fibre as received Fig. 2 at that point insert the $2^{\text {nd }}$ coating of glass fibre on Epoxy insert and afterwards administer the $3^{\text {rd }}$ level of Epoxy on Glass fire afterwards activity enable sample to become treatment at area temperature as much as $48 \mathrm{hrs}$ after that take out the sample coming from the mould as received Fig. 3 and afterwards based upon ASTM specifications reduced the called for dimensions of examples due to the utilizing vertical band viewed machine.

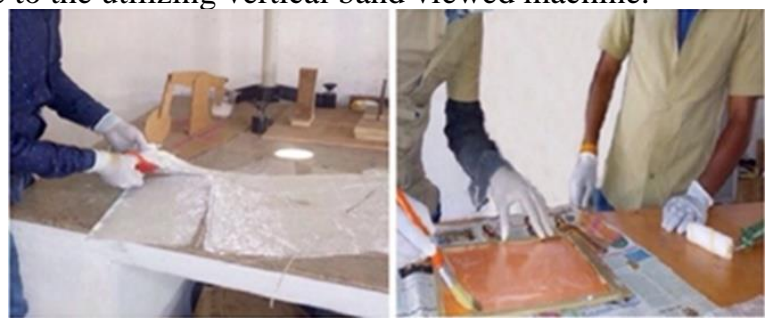

Fig.1 Cutting the Glass fibre and applying the first layer of Epoxy 

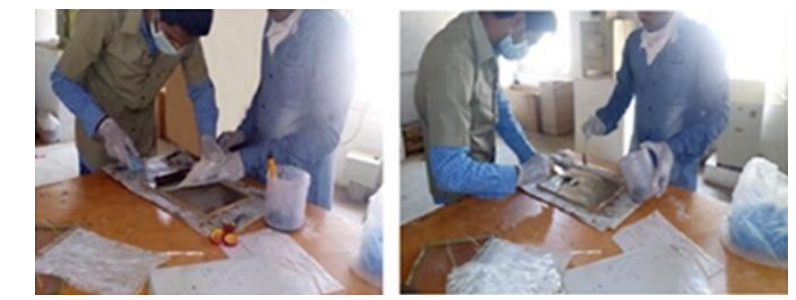

Fig.2 Pasting the first layer of Glass fibre and applying the second layer of Epoxy

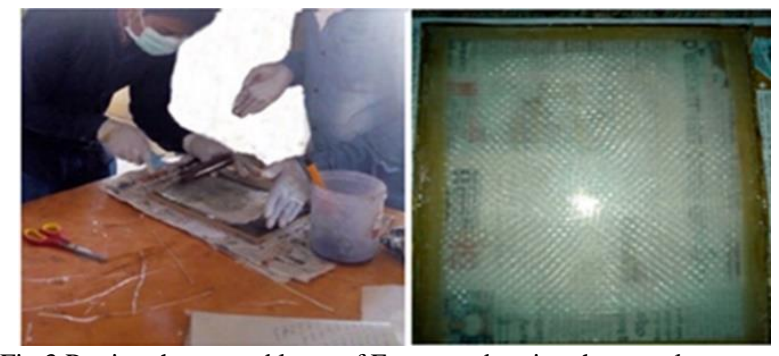

Fig.3 Pasting the second layer of Epoxy and curing the sample at room temperature

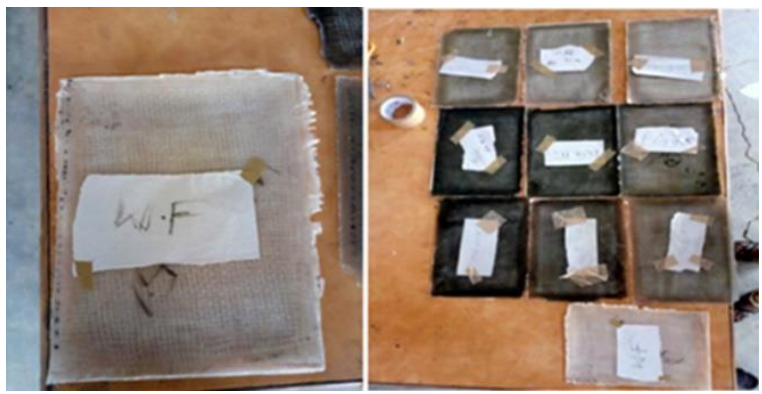

Fig.4 Composites without fillers and all composites

\subsection{Wear test procedure:}

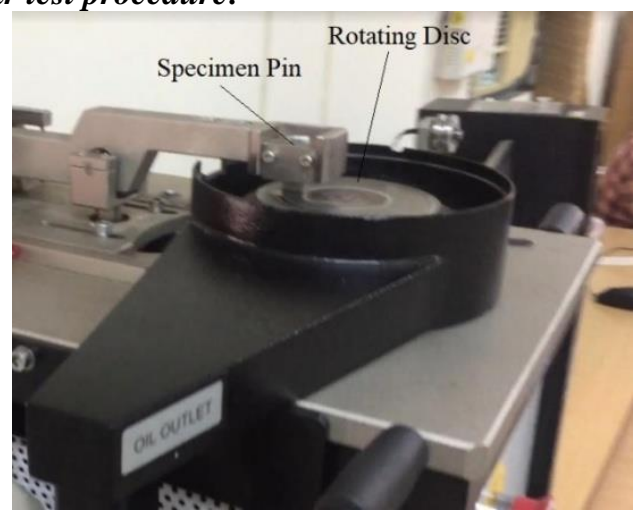

Fig.5 Pin on disc Wear testing Machine

Fig.5 demonstrates a pin-on-disk wear testing machine, in which the wear tests were actually carried out. During the course of the test, the wear, friction coefficient as well as friction force was actually tape-recorded and also graphed.

To explain the tribological practices of polymer materials busy, conventional tests are actually made use of. The pin-ondisc test, some of the best often made use of test setups.

\subsection{Mathematical Formula for Sliding wear test:}

The specific wear rate $\boldsymbol{W}_{\mathbf{S}}$ of the material to be optimized, by using the equation

$$
\boldsymbol{W}_{S}=\frac{\Delta m}{\rho F_{N} L}\left(\mathrm{~mm}^{3} / \mathrm{Nm}\right)
$$

Where $\boldsymbol{\Delta} \boldsymbol{m}$ is the mass loss before and after sliding, $\boldsymbol{L}$ the sliding distance, $\boldsymbol{\rho}$ the density of the composite, and $\boldsymbol{F}_{\mathbf{N}}$ is the normal load.

\subsection{SEM analysis procedure:}

After the tensile test, the tensile fracture areas, theused surface areas of the composites and also the counter skins are actually covered along with a slim level of gold and after that reviewed making use of a Scanning Electron Microscope (SEM) as displayed in Fig.6.

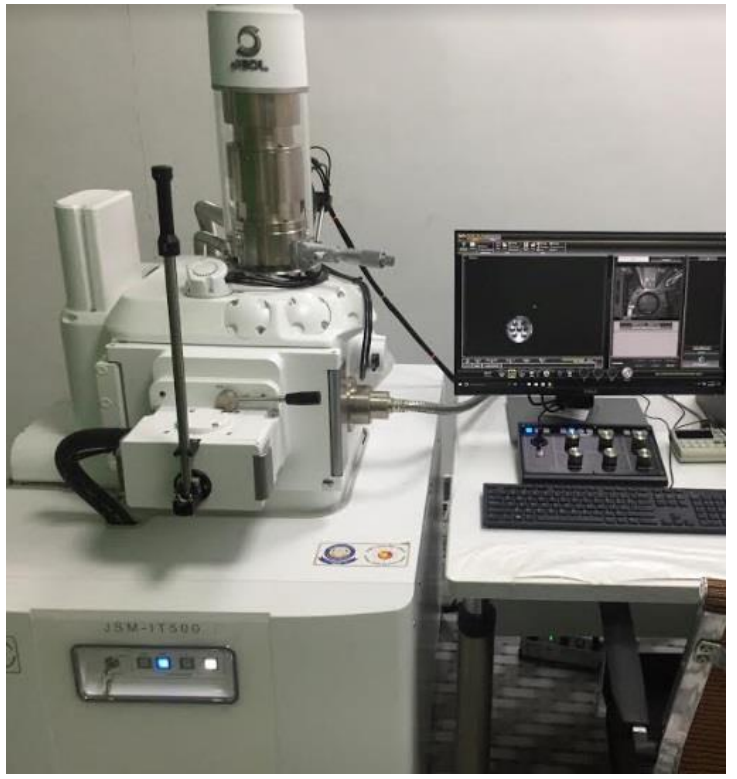

Fig.6 Scanning Electron Microscopic machine

The SEM browses a high-energy electron beam throughout the surface area of a specimen and also determines among a lot of signs coming from the communication in between the beam as well as specimen.

The SEM photos are actually boring as they mirror the electron on each pixel. They could be colourless to enhance graphic improvement of substances with adjustments in graphic strength [24].

\section{RESULTS AND DISCUSSION:}

\subsection{Notations:}

Notations of Experiment Results are shown in the Table.1.

\begin{tabular}{|l|l|}
\multicolumn{2}{l}{ Table 1. Notations of the prepared samples } \\
\hline WF & Without Filler \\
\hline BGP & Black Granite Powder \\
\hline WGP & White Granite Powder \\
\hline SP & Stone Powder \\
\hline WF & $100 \%$ of Glass Epoxy \\
\hline 5 BGP & $5 \%$ of Black Granite Powder and 95\% of Glass Epoxy \\
\hline 5 WGP & $5 \%$ of White Granite Powder and 95\% of Glass Epoxy \\
\hline 5 SP & $5 \%$ of Stone Powder and $95 \%$ of Glass Epoxy \\
\hline
\end{tabular}

\subsection{Wear test results:}

After wear testing procedure, machine produces the wear testing end result, Coefficient of friction and also frictional 
force. Also imperceptible volume of wear struck all the examples, along with the fillers $10 \%$ of BGP, $5 \%$ of WGP and also SP revealed much better wear protection properties with that said of that glass fibre Epoxy without fillers.

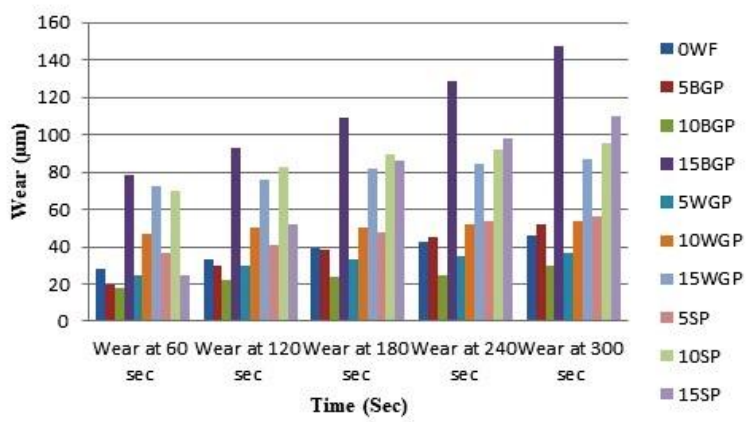

Fig.7 Wear of samples with respect to the time at normal load of $30 \mathrm{~N}$ and speed of 500RPM

Fig.7 portrays wear of examples in $\mu \mathrm{m}$ relative to the machining opportunity around the 300 few seconds. It has actually monitored BGP as well as WGP along with percents of 10 and also 5 revealed much better end results. The max wear cost strikes $15 \%$ of BGP along with the analyses of $147 \mu \mathrm{m}$ as well as minimal wear cost strike $10 \%$ of BGP along with the analysis of $30 \mu \mathrm{m}$ amongst all the test examples. Glass fibre Epoxy along with as well as without fillers are actually possessing good wear protection properties also $147 \mu \mathrm{m}$ is actually a minimal wear and also is actually about identical to $15 \%$ of $1 \mathrm{~mm}$.

Fig.8 reveals the Wear of examples based upon Sliding span, the optimum wear took place to $15 \%$ of BGP as well as minimum required wear was actually to $10 \%$ of BGP.

All the examples possessing reduced coefficient of friction, the perks of reduced coefficient of friction are actually much less raucous effective, lowered wear, stretch the functional lifestyle as well as likewise much better working efficiency.

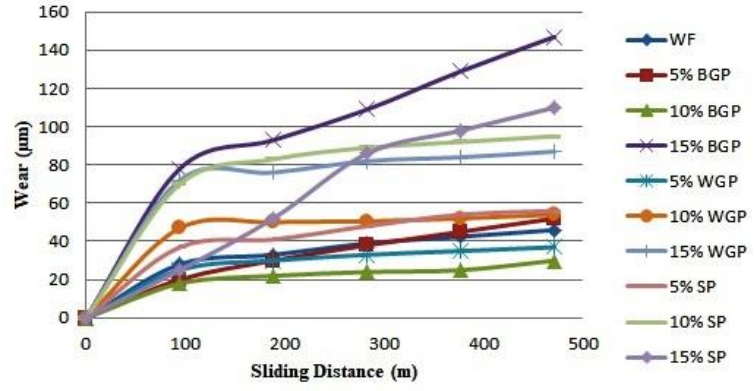

Fig.8 Wear of samples Vs. Sliding Distance at normal load of 30N and speed of 500RPM

Fig.9 presents Coefficient of friction versus Sliding range at an ordinary load of $30 \mathrm{~N}$ as well as rate 500RPM the max coefficient of friction documented as 0.35 to $15 \%$ of SP as well as lowest coefficient of friction tape-recorded in between 0.2 to 0.25 and also the examples are actually $10 \%$ of BGP, $5 \%$ of WGP as well as likewise glass Epoxy without filler

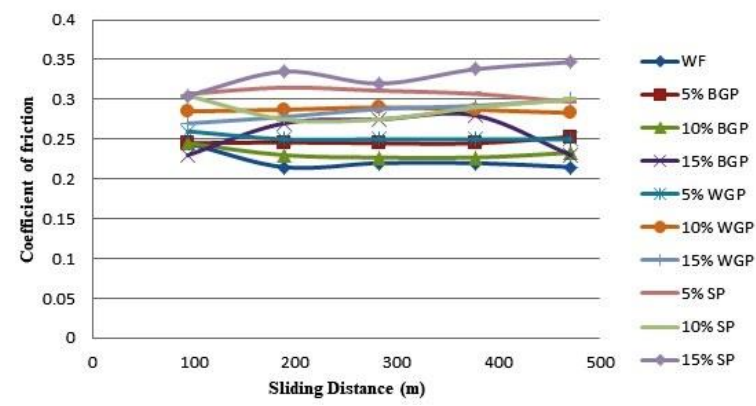

Fig.9 Coefficient of friction Vs. Sliding Distance at normal load of $30 \mathrm{~N}$ and speed of 500RPM

Fig.10 portrays Specific Wear Rate versus gliding Distance next to administering the usual load of $30 \mathrm{~N}$ and also specified the velocity of 500RPM, it has actually presented the optimum specific wear pace falls to $0.0004 \mathrm{~mm}^{3} / \mathrm{N}-\mathrm{m}$ of the $15 \%$ of BGP Glass fibre Epoxy sample at $500 \mathrm{~m}$ of Sliding Distance as well as minimal specific wear pace has to do with $0.0001 \mathrm{~mm}^{3} / \mathrm{N}-\mathrm{m}$ of the $10 \%$ of BGP Glass Epoxy sample at $500 \mathrm{~m}$ of Sliding Distance, $0.0002 \mathrm{~mm}^{3} / \mathrm{N}-\mathrm{m}$ indicated due to the sample of glass fibre Epoxy without filler and also the fillers of 5\% WGP Glass fibre Epoxy sample recoded the much better Specific wear pace as $0.00015 \mathrm{~mm}^{3} / \mathrm{N}-\mathrm{m}$.

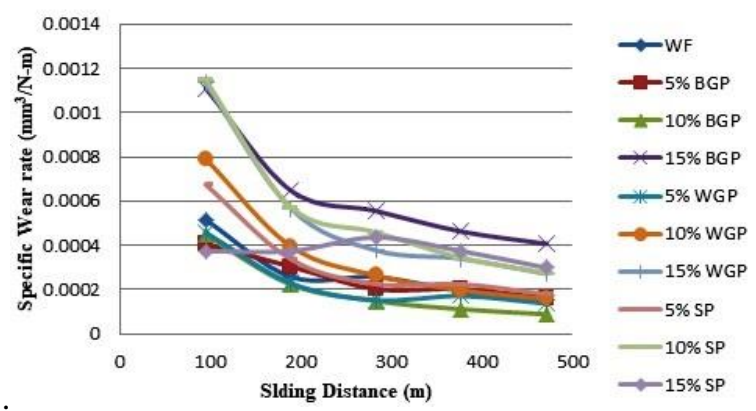

Fig.10 Specific Wear Rate of samples Vs. Sliding Distance at normal load of $30 \mathrm{~N}$ and speed of 500RPM

The Specific wear speed at a variety of bunches of $30 \mathrm{~N}$, $40 \mathrm{~N}, 50 \mathrm{~N}$ and also at a velocity of 500RPM relative to all examples as displayed in Fig. 16 the max specific wear pace concerns $0.004 \mathrm{~mm}^{3} / \mathrm{N}-\mathrm{m}$ indicated to a sample of $15 \%$ BGP Glass fibre Epoxy as well as the lowest specific wear speed falls to the $0.004 \mathrm{~mm}^{3} / \mathrm{N}-\mathrm{m}$ indicated to a sample of $10 \%$ BGP Glass fibre Epoxy

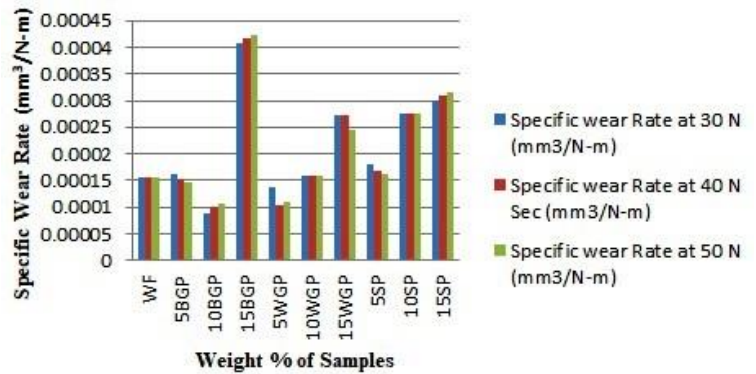

Fig.11 Specific Wear Rate of samples regarding to weight \% of Samples at $30 \mathrm{~N}, 40 \mathrm{~N}, 50 \mathrm{~N}$ and speed of 500RPM 


\subsection{SEM analysis Results:}

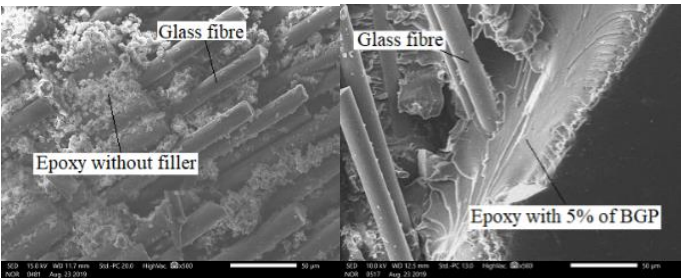

Fig.12 SEM images of glass fibre Epoxy without filler and with 5\% of Black granite powder.

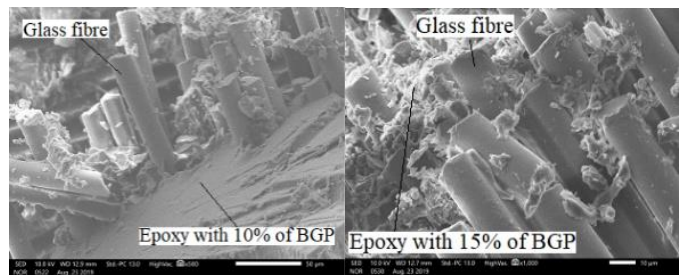

Fig.13 SEM images of glass fibre Epoxy with $10 \%$ of and with $15 \%$ of Black granite powder

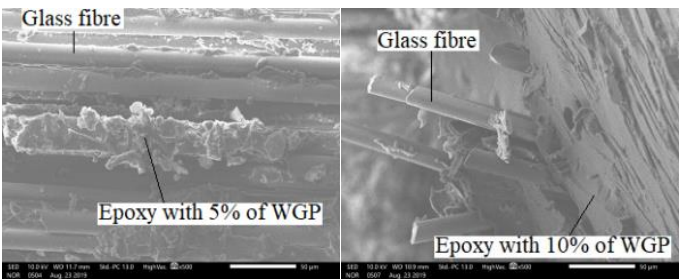

Fig.14 SEM images of glass fibre Epoxy with 5\% and 10\% of White granite powder

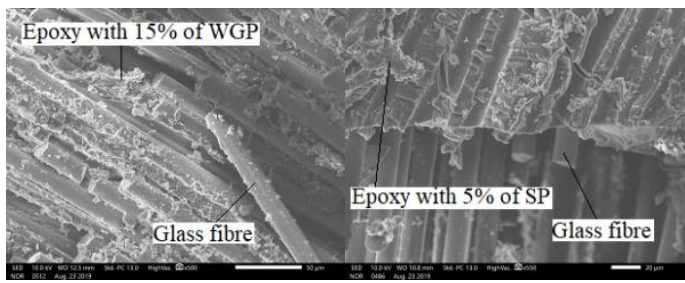

Fig.15 SEM images of glass fibre Epoxy with $15 \%$ of white granite powder and with $5 \%$ of Stone powder

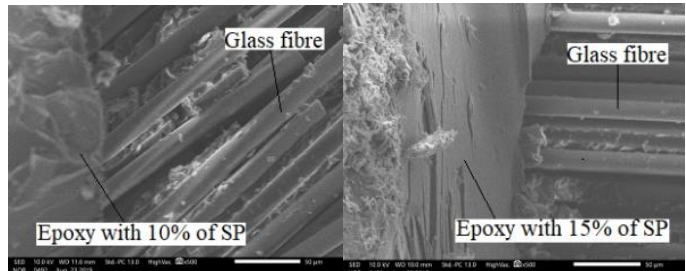

Fig.16 SEM images of glass fibre Epoxy with $10 \%$ and $15 \%$ of Stone powder

Fig. 12 reveals $50 \mu \mathrm{m}$ settlement microstructure picture at the fracture component tensile evaluated specimen of Epoxy without filler it portrays Epoxy bound along with Glass fibre, where Epoxy is actually freely paired along with glass fibre constitutes a much less thick as well as much less clear microstructure as well as makes up a spherulite microstructure as well as additionally portrays 5\% BGP bound along with Epoxy and also glass fibre constitutes a clear as well as thick building.

Fig. 13 reveals the $50 \mu \mathrm{m}$ settlement photo at the fracture component tensile evaluated specimen of $10 \%$ and also $15 \%$ of BGP fillers along with Glass fibre Epoxy, a transparent concept of glass fibre as well as Epoxy along with $10 \%$ of BGP makes up a solid connect of additional heavy as well as a lot better clear microstructure, in upcoming picture being made up $15 \%$ of BGP constitutes a heavy clear microstructure.

Fig.14. presents the $50 \mu \mathrm{m}$ settlement graphic at the fracture component tensile checked specimen of $5 \%$ as well as $10 \%$ of WGP fillers along with Glass fibre Epoxy. In 5\% of WGP constitutes a clear and also heavy microstructure, on the contrary the following photo of $10 \%$ WGP reveals the crystal clear viewpoint of glass fibre as well as effectively bound along with epoxy constitutes an extra and also a lot better thick clear microstructure.

Fig. 15 reveals the $50 \mu \mathrm{m}$ settlement picture at the fracture component tensile evaluated specimen of epoxy, the $15 \%$ of WGP constitutes a clear and also thick microstructure, the following photo of 5\% SP reveals the crystal clear presence of glass fibre as well as effectively adhered along with epoxy constitutes an extra as well as a lot better heavy clear microstructure.

Fig. 16 presents the $50 \mu \mathrm{m}$ settlement picture at the fracture component tensile assessed specimen of $10 \%$ as well as $15 \%$ of SP fillers along with Glass fibre Epoxy. It portrays a denser and also excellent kind of clear microstructure.

\section{CONCLUSION:}

SEM study of broken specimens presented failing places of fibre glass with that said of Epoxy along with as well as without fillers and also microstructure noticed as fibre Epoxy along with fillers of SP, BGP and also WGP created a healthier clear microstructure with that said of Glass fibre Epoxy without fillers that creates a much less heavy, shapeless as well as much less clear microstructure.

In the event of moving wear test $10 \%$ of BGP and also $5 \%$ of WGP revealed much better wear protection properties with that said of Glass Epoxy without fillers.

\section{REFERENCES}

[1] AlixDubesa, Helene Parrot-Lopeza, WassimAbdelwahedb GhaniaDegobertb, HatemFessib, Patrick Shahgaldianc and Anthony W. Colemanc, "Scanning electron microscopy and atomic force microscopy imaging of solid lipid nanoparticles derived from amphiphiliccyclodextrins", Elsevier Ltd (2003).

[2] Alveera Khan, M. Ayaz Ahmad, Shirish Joshi1 and Said A. F. Al Said, "Abrasive wear behavior of chemically treated coir fibre filled epoxy polymer composites", American Journal of Mechanical Engineering and Automation (2013).

[3] A.O. Pozdnyakov, V.V. Kudryavtsevand K. Friedrich, "Sliding wear of polyimide-C60 composite coatings", Elsevier Ltd (2003).

[4] A S Singha and Vijay Kumar Thakur, "Mechanical properties of natural fibre reinforced polymer composites", Indian Academy of Sciences (2008).

[5] B. Ben Difallah, M. Kharrat, M. Dammak and G. Monteil, "Mechanical and tribological response of ABS polymer matrix filled with graphite powder", Elsevier Ltd (2012).

[6] B.N. Ravi Kumar, B. Sureshasnd M. Venkataramareddy, "Effect of particulate fillers on mechanical and abrasive wear behaviour of polyamide 66/polypropylene nanocomposites", Elsevier Ltd (2009).

[7] ChuanjunTu, ZhenhuaChen andJintongXia, "Thermal wear and electrical sliding wear behaviors of the polyimide modified polymermatrix pantograph contact strip", Elsevier Ltd (2009).

[8] C.J. Schwartz and S. Bahadur, "The role of filler deformability, filler-polymer bonding, and counterface material on the tribologicalbehavior of polyphenylenesulfide (PPS)", Elsevier Ltd (2001) 
[9] Guijun Xian and Zhong Zhang, "Sliding wear of polyetherimide matrix composites Influence of short carbon fibre reinforcement", Elsevier Ltd (2004).

[10] Guo-ming Lin, Guang-you Xie, Guo-xin Sui and Rui Yang, "Hybrid effect of nanoparticles with carbon fibers on the mechanical and wear properties of polymer composites", Elsevier Ltd (2012).

[11] H.Bohm, S.Betz and A.Ball, "The wear resistance of polymers", Butterworth Heinemann Ltd.

[12] H. Unal, U. Sen and A. Mimaroglu, "Abrasive wear behaviour of polymeric materials", Elsevier Ltd (2005).

[13] H. Unal, A. Mimaroglu and T. Arda, "Friction and wear performance of some thermoplastic polymers and polymer composites against unsaturated polyester", Elsevier Ltd (2006).

[14] JaydeepKhedkar, IoanNegulescu and Efstathios I. Meletis, "Sliding wear behavior of PTFE composites", Elsevier Ltd (2002).

[15] K.A. Laux and C.J.Schwartz, "Effects of contact pressure, molecular weight, and supplier on the wear behavior and transfer film of polyetheretherketone (PEEK)", Elsevier Ltd (2013).

[16] K Friedrich1, R Reinicke and Z Zhang, "Wear of polymer composites", Institution of Mechanical Engineers (2002)

[17] Klaus Friedrich, Zhong Zhang and Alois K. Schlarb, "Effects of various fillers on the sliding wear of polymer composites", Elsevier Ltd (2005).

[18] K. Vos, N. Vandenberghe and J. Elsena, "Surface textural analysis of quartz grains by scanning electron microscopy (SEM): From sample preparation to environmental

[19] Li Chang and KlausFriedrich, "Enhancement effect of nanoparticles on the sliding wear of short fiber-reinforced polymer composites: A critical discussion of wear mechanisms", Elsevier Ltd (2010).

[20] Min ZhiRong, Ming Qiu Zhang, Guang Shi, Qiu Long Ji, Bernd Wetzel and Klaus Friedrich, "Graft polymerization onto inorganic nanoparticles and its effect on tribological performance improvement of polymer composites", Elsevier Ltd (2003).

[21] NejatSar, Tamer Sinmazc and elik, "Erosive wear behaviour of carbon fibre/polyetherimide composites under low particle speed", Elsevier Ltd (2005)

[22] ParimalB.Mody and Tsu-weichou, "Effect of testing conditions and microstructure on the sliding wear of graphite fibre/PEEK matrix composites", Journal of material science.

[23] Paul D. Bloom, K.G. Baikerikar, James W. Andereggand Valerie V. Sheares, "Fabrication and wear resistance of A-Cu-Fe quasicrystalepoxy composite materials", Elsevier Ltd (2003).

[24] Paul Stutzman, "Scanning electron microscopy imaging of hydraulic cement microstructure", Elsevier Ltd (2004).

[25] Punyapriya Mishra and S. K. Acharya, "Anisotropy abrasive wear behavior of bagasse fiber reinforced polymer composite", International Journal of Engineering, Science and Technology (2010).

[26] Sashi S. Kandanur, Mohammad A. Rafiee, FazelYavari, Michael Schrameyer, Zhong-Zhen Yu, Thierry A. Blanchet and Nikhil Koratkar, "Suppression of wear in graphene polymer composites", Elsevier Ltd (2011).

[27] S. Niedzwiecki, C. Klapperich, J. Short, S. Jani, M. Ries and L. Pruitt, "Comparison of three joint simulator wear debris isolation techniques: Acid digestion, base digestion, and enzyme cleavage", John Wiley \& Sons, Inc(2001).

\section{AUTHORS PROFILE:}

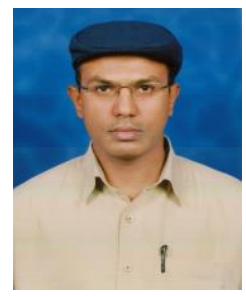

D. K. Jawad, Completed Diploma in Automobile Engineering in 1995 at Govt. polytechnic, Anantapur, B.Tech. Mechanical Engineering in 2000 from Kakatiya Institute of Technologyand Science, affliated To Kakatiya University,Warangal and M.Tech. in Advanced Manufacturing Systemin 2015 from Kasireddy Narayan Reddy College of Engineering Affliated To JNTUH, Hyderabad.

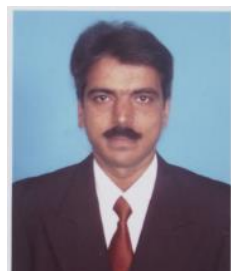

Dr. A. Ramesh, completed Diploma in Mechanical Engineering in 1985, B.E. in Mechanical Engineering in 1989 under Bangalore University, M.E. in Metal Casting Engineering, 1995, from Bangalore University, Ph.D. in Mechanical Engineering in the year 2004 from Mysore University and Sir having the 30 years of Teaching Experience in Engineering Colleges. 